\title{
Compliance with physical activity health recommendations in members of non-governmental organizations promoting active lifestyle
}

\author{
Małgorzata Dębska' ${ }^{1, A-D, F}$, Władysław Mynarski ${ }^{1, A, C-F}$, Elżbieta Biernat ${ }^{2, D-F}$, Agnieszka Nawrocka ${ }^{1, D-F}$, \\ Barbara Bergier,E-F \\ 1 Jerzy Kukuczka Academy of Physical Education, Katowice, Poland \\ 2 School of Economics, Warsaw, Poland \\ ${ }^{3}$ Pope John Paul II State School of Higher Education, Biała Podlaska, Poland \\ A - Research concept and design, B - Collection and/or assembly of data, C - Data analysis and interpretation, \\ $D$ - Writing the article, E - Critical revision of the article, F - Final approval of article
}

Dębska M, Mynarski W, Biernat E, Nawrocka A, Bergier B. Compliance with physical activity health recommendations in members of nongovernmental organizations promoting active lifestyle. Ann Agric Environ Med. 2019; 26(1): 109-113. doi: 10.26444/aaem/94293

\begin{abstract}
Introduction. A vital role in health maintenance and the prevention of non-communicable chronic diseases is played by an adequate level of physical activity. In recent decades, numerous guidelines have been developed to determine the criteria of physical activity levels that are essential to obtain overall health benefits.

Objective. The aim of the presented study was evaluation of the physical activity of adult members of non-governmental organizations promoting active lifestyle, in compliance with recommendations of the World Health Organization and the American College of Sport Medicine.

Materials and method. The study examined 95 adult members of non-governmental organizations (NGOs) promoting an active lifestyle in the Silesian Province of Western Poland. In order to make a comprehensive physical activity evaluation (including all criteria of most complex health-recommendations), both an objective tool (ActiGraph GT3X) and a subjective tool (Daily Physical Activity Log) were used.

Results. Compliance with a weekly total time of moderate to vigorous aerobic efforts were observed in $47 \%$ of women and $44 \%$ of men with regard to WHO guidelines, and in $29 \%$ of women and $23 \%$ of men, respectively, regarding ACSM guidelines. The criterion for the frequency of strength exercises was met by $24 \%$ of women and $15 \%$ of men. Flexibility exercises level was adequate in $35 \%$ of women and $28 \%$ of men.

Conclusions. The most frequent cause of non-meeting the criteria of the above- mentioned organisations were insufficient frequency of the weekly resistance (strength) exercises and flexibility exercises. There is a need to create public health programmes based on the complex physical activity recommendations, including all types of physical efforts (aerobic, strength, flexibility), and to emphasise the fact that meeting all of them is essential to obtain overall health benefits.
\end{abstract}

Key words

adults, lifestyle, accelerometry, health behaviours, non-governmental organizations, health recommendations

\section{INTRODUCTION}

A vital role in health-oriented human behaviours is played by an adequate level of physical activity. In recent decades, numerous recommendations have been developed to determine the criteria for physical activity (PA) levels that are essential for maintaining or improving the health status $[1,2,3]$, and the levels recommended for the prevention and treatment of non-communicable chronic diseases (NCDs) $[4,5,6,7,8]$. A constant evolution of the views in this area is being observed, whereas the number of prerequisite criteria and their minimal level are being raised [9].

Contemporary recommendations provide the comprehensive quantitative (e.g. weekly frequency and duration) and qualitative (exercise intensity and type)

Address for correspondence: Małgorzata Dębska The Jerzy Kukuczka Academy od Physical Education, 3 Maja 17a/11, 41-300 Dąbrowa Górnicza, Poland e-mail: mal.debska@interia.pl

Received: 25.05.2018; accepted: 14.08.2018; first published: 14.09.2018 criteria to evaluate the level of physical activity needed to improve or maintain an adequate health status. A new mainstream has emerged for scientific explorations, with real PA in people at different ages being compared with the health criteria contained in the recommendations [10, $11,12,13]$. For example, these surveys have found that the percentage of men and women involved in physical activity at the recommended level is on the increase $[14,15,16]$, although men and women over age of 35 rarely met the criteria of healthy physical activity, compared to people from younger populations [17], while the lowest number met the recommendations concerning vigorous exercise $[12,14,15$, 17]. The surveys also found that the percentage of people who met the physical activity recommendations tended to decrease as the number of evaluation criteria rose [11].

Extending knowledge in this area seems to be indispensable in the context of searching for good practices for the promotion of physical activity in public health prevention programmes. This concerns, for example, identification of the individual 
criteria of the recommended physical activity which are mostly neglected across various social and professional groups. Consequently, this is likely to substantially facilitate the development of physical activity programmes for various groups of people.

The most recent recommendations promoted by WHO [18] and ACSM [19] emphasize that only moderate-intensity exercise can be regarded as providing health benefits $(>3$ METs). Adults can be involved in such exercise mostly in their leisure time, e.g., in associations which promote healthy lifestyles through intentional physical activity. These groups are becoming a natural base for scientific explorations in this area of research as they are formed by people guided by coaches, with a naturally larger-than-average level of physical activity.

\section{OBJECTIVES}

The study is focused on identification of the percentage of people (in the group of members of selected associations that promote healthy lifestyles) who meet all the criteria of PA level recommended by the WHO and ACSM. Individual criteria not met by the respondents were also identified.

The secondary aim of the study was to draw attention to the necessity for comprehensive physical activity assessment, taking into account all the criteria of health-oriented recommendations, enabling comparison of the different social groups in terms of PA level, and assessment of the effectiveness of public health practices based on its results.

\section{MATERIALS AND METHOD}

The study group comprised of women and men who were involved in regular physical activity as members of nongovernmental organizations (NGOs) that promote healthy lifestyle. These are non-profit organizations focused mainly on the popularization of different forms of leisure-time physical activity, especially by organizing open recreational training sessions, trips (cycling, hiking) and amateur competitions. The above-mentioned associations are usually established by enthusiasts of recreational sports and associate people looking for company to spend their free time. The typical workouts in such organizations were scheduled three times weekly and lasted 90-120 minutes, with the major part being endurance efforts in spring and summer, and general fitness training in autumn and winter. Participation in organized training sessions is usually complimentary and open to everyone.

The survey was conducted in four out of eight NGOs oriented towards physical activity promotion in the western part of the Silesian Province of Poland. The study group comprised 95 people, accounting for $78 \%$ of the all members of the above-mentioned organizations. Over $40 \%$ of participants (11 women and 28 men) did not meet all the research procedures. This was mainly due to the requirement of wearing an activity monitor for at least one week and recording the self-reported activity in the Daily Physical Activity Log simultaneously (20 people).

All subjects provided written consent for the use of information collected during examination. The study was approved by Jerzy Kukuczka Academy of Physical Education Research and Ethics Committee (02/2012).
Statistical analysis was performed for 17 women (aged $31 \pm 9$ years) and 39 men ( $37 \pm 9$ years), who were involved in the full research programme, including:

1. Weekly monitoring of habitual physical activity of the men and women using the three-axial ActiGraphGT3X Plus activity monitor (ActiGraph Company, Pensacola FL, USA) and the ActiLife 5.10 software to analyse the data. The following information was derived:

- weekly total time of moderate-intensity aerobic physical activity (MPA [min/week]) and vigorous physical activity (VPA [min/week]);

- frequency of physical activity throughout the week with the above intensity levels (MPA [day/week], VPA [day/ week]).

2. Self-reported parameters of strength exercises (SE) and flexibility exercises (FE). For this purpose, the participants were asked to record adequate information in the of Daily Physical Activity Log.

Based on the records in the Daily Physical Activity Log, the form and type of physical activity (endurance, strength and flexibility exercises) and their duration (from ... to ...) were identified. The declared type of physical exercise was verified by comparison with the self-reported form of exercise (jogging, Nordic walking, cycling, machine or weight workout, stretching and relaxation exercises, etc.).

Intensity of endurance exercises was defined using ActiLife 5.10 software (low, moderate, vigorous). Duration of strength and flexibility exercises declared in the Daily Physical Activity Log was verified with activity recorded by the activity monitor. Consistency of the declared and recorded times of activity was adopted as a criterion of credibility of the records in the Activity Log. Non-meeting this criterion led to the reduction by $20 \%$ in the number of people who were included in the full programme of the studies The research procedure allowed for a reliable evaluation of meeting of all the criteria for healthy level of physical activity recommended by the ACSM and WHO, which represented the cognitive aim of the study.

3. Measurements of body height, body mass, body fat (\%), waist circumference and hip circumference were conducted with ananthropometer, flexible centimetre tape and BC418 Segmental Body Composition Analyzer produced by Tannita. The collected data allowed for computation of BMI and WHR indices.

Information about parameters of physical activity (points $1,2)$ was compared with individual criteria and their full sets from health-oriented recommendations by the WHO [18] and ACSM [19].

Statistical analysis. Involved computation of the basic parameters of descriptive statistics for all the variables, and determination of the percentage of people who met the full recommendations and their individual criteria according to the WHO [18] and ACSM [19]. The computations were made separately for gender groups; however, in consideration of the relatively high disproportion between the number of women (17) and men (39) who participated in the study, which is typical of the associations studied, interpretation of the results was based on total data obtained for the entire study group. This approach is justified because the men and women followed the same training regimens during the activities organized by the associations, and the physical 
activity recommendations for health for both male and female adults were the same.

Statistical reasoning was conducted for the significance level set at $\mathrm{p}<0.05$. Statistica 10 software (StatSoft, Inc.) was used for the computations.

\section{RESULTS}

The majority of the study participants had proper body build (Tab. 1).

Table 1. Somatic parameters of study participants

\begin{tabular}{lccc}
\hline \multirow{2}{*}{ Body composition } & Female $\mathrm{n}=17$ & Male $\mathrm{n}=39$ & Total $\mathrm{n}=56$ \\
\cline { 2 - 4 } & $\overline{x x} \pm \mathrm{SD}$ & $\overline{x x} \pm \mathrm{SD}$ & $\overline{x x} \pm \mathrm{SD}$ \\
\hline Body mass [kg] & $57.9 \pm 7.5$ & $75.5 \pm 9.7$ & $70.2 \pm 12.2$ \\
\hline Body fat [\%] & $21.9 \pm 6.6$ & $14.8 \pm 5.7$ & $16.9 \pm 6.8$ \\
\hline BMI [kg/m²] & $21.9 \pm 2.5$ & $24.0 \pm 3.1$ & $23.3 \pm 3.0$ \\
\hline WHR [j.u.] & $0.8 \pm 0.1$ & $0.9 \pm 0.1$ & $0.87 \pm 0.08$ \\
\hline
\end{tabular}

WHR - waist to hip ratio

In the monitored week, all the participants performed aerobic physical activity, with $32 \%$ of them performing flexibility exercises and $21 \%$ involved in strength workouts (Tab. 2).

Table 2. Parameters of participants' physical activity

\begin{tabular}{|c|c|c|c|c|c|c|c|}
\hline \multirow{2}{*}{\multicolumn{2}{|c|}{ Parameters of physical activity }} & \multicolumn{2}{|c|}{ Female $n=17$} & \multicolumn{2}{|c|}{ Male $n=39$} & \multicolumn{2}{|c|}{ Total $n=56$} \\
\hline & & $n$ & $\overline{x x} \pm \mathrm{SD}$ & $\mathrm{n}$ & $\overline{x x} \pm S D$ & $\mathrm{n}$ & $\overline{x x} \pm \mathrm{SD}$ \\
\hline \multirow{6}{*}{$\mathrm{AE}$} & MPA [min/week] & 17 & $607 \pm 184$ & 39 & $810 \pm 371^{*}$ & 56 & $749 \pm 337$ \\
\hline & $\begin{array}{l}\text { MPA } 10 \text { min bouts } \\
{[\mathrm{min} / \text { week }]}\end{array}$ & 16 & $143 \pm 103$ & 36 & $150 \pm 148^{\text {ns }}$ & 52 & $148 \pm 134$ \\
\hline & $\begin{array}{l}\text { MPA } 10 \text { min bouts } \\
\text { [day/week] }\end{array}$ & 16 & $3.4 \pm 1.8$ & 36 & $3.4 \pm 1.7^{\mathrm{ns}}$ & 52 & $3.4 \pm 1.7$ \\
\hline & VPA [min/week] & 17 & $98 \pm 90$ & 35 & $74 \pm 96^{\mathrm{ns}}$ & 52 & $82 \pm 73$ \\
\hline & $\begin{array}{l}\text { VPA } 10 \text { min bouts } \\
{[\mathrm{min} / \text { week }]}\end{array}$ & 10 & $70 \pm 45$ & 12 & $117 \pm 102^{\text {ns }}$ & 22 & $95 \pm 83$ \\
\hline & $\begin{array}{l}\text { VPA } 10 \text { min bouts } \\
\text { [day/week] }\end{array}$ & 10 & $2.0 \pm 1.2$ & 12 & $2.3 \pm 1.4^{\mathrm{ns}}$ & 22 & $2.1 \pm 1.2$ \\
\hline \multirow{2}{*}{ SE } & SE [min/week] & 4 & $135 \pm 57$ & 8 & $156 \pm 94^{\text {ns }}$ & 12 & $149 \pm 82$ \\
\hline & SE [day/week] & 4 & $2.3 \pm 0.5$ & 8 & $3.0 \pm 1.5^{\mathrm{ns}}$ & 12 & $2.8 \pm 1.3$ \\
\hline \multirow{2}{*}{$\mathrm{FE}$} & FE [min/week] & 8 & $68 \pm 80$ & 10 & $55 \pm 35^{\mathrm{ns}}$ & 18 & $61 \pm 49$ \\
\hline & FE [day/week] & 8 & $2.9 \pm 2.4$ & 10 & $4.0 \pm 1.3^{\mathrm{ns}}$ & 18 & $3.5 \pm 1.9$ \\
\hline
\end{tabular}

The study participants of both gender groups performed moderate-intensity exercises more often (MPA 10 min bouts - 3 days/week) than vigorous exercise (VPA 10 min bouts - 2 days/week). The same pattern was found for the duration of moderate and vigorous-intensity physical activity. Similar tendencies were observed for strength exercises (Tab. 2). The statistically significant differences between the gender groups for time of moderate physical activity (MPA) were found only in flexibility exercises (FE), with men obtaining better results (Tab. 2).

Basic criterion for healthy physical activity according to the WHO (150 min MPA or 75 min VPA/week or equivalent of these parameters) was met by $45 \%$ of the respondents $(47 \%$ of women and $44 \%$ of men). Recommended PA level in terms of strength exercises (SE) was found in $18 \%$ of participants (women 24\%; men 15\%). All the criteria of the WHO recommendations were met by $18 \%$ (women $24 \%$; men $15 \%$ ) (Tab. 3).

Table 3. Percentages of participants meeting the criteria of WHO and ACSM health recommendations

\begin{tabular}{lllll}
\hline \multirow{2}{*}{$\begin{array}{l}\text { Recommen- } \\
\text { dation }\end{array}$} & Criterion & Female & Male & Total \\
\cline { 2 - 5 } & $\begin{array}{l}\text { AE:150 min MPA or } 75 \text { min VPA or } \\
\text { equivalent per week }\end{array}$ & (n) $\%$ & (n) $\%$ \\
\cline { 2 - 5 } WHO & SE: 2 days/week 47 & (17) 44 & (25) 45 \\
\cline { 2 - 5 } & All recommendation's criteria & (4) 24 & (6) 15 & (10) 18 \\
\hline \multirow{4}{*}{ ACSM } & AE: 5 days 30 min MPA or 3 days VPA & (6) 15 & (10) 18 \\
\cline { 2 - 5 } & 20 min or equivalent/week & (5) 29 & (9) 23 & (14) 25 \\
\cline { 2 - 5 } & SE: 2 days/week & (4) 24 & (6) 15 & (10) 18 \\
\cline { 2 - 5 } & FE:2-3 days/week & (6) 35 & (11) 28 & (17) 30 \\
\cline { 2 - 5 } & All recommendation's criteria & - & (1) 2 & (1) 2 \\
\hline
\end{tabular}

AE - aerobic exercises; MPA - moderate physical activity; VPA - vigorous physical activity; $\mathrm{SE}$ - strength exercises; $\mathrm{FE}$ - flexibility exercises

The ACSM criterion of recommended aerobic exercises (AE, 5 days, $30 \mathrm{~min}$ MPA or 3 days, $20 \mathrm{~min}$ VPA per week accumulated in at least 10 -min bouts) was met by $25 \%$ of the participants ( $29 \%$ of the women and $23 \%$ of the men). Recommendations for strength exercise (SE, 2 days/ week) were fulfilled by $18 \%$ of the members of associations (women 24\%; men 15\%), whereas flexibility exercises (FE, 2-3 days/week) were performed by $30 \%$ of the participants (women 35\%; men 28\%). All the requirements of ACSM recommendations was met by only $2 \%$ of the study group members (one man) (Tab. 3).

Gender was not a factor that significantly determined meeting both individual criteria and full recommendations for healthy level of physical education, according to WHO and ACSM, with p for $\mathrm{chi}^{2}$ test $>0.05$ (Tab. 3).

\section{DISCUSSION}

In the study, the percentage of members of associations that promote healthy lifestyle and who were involved in physical activity at the level recommended for health, according to WHO and ACSM, was evaluated. The criteria for guidelines which were most frequently not met by the participants were also identified. Consequently, the opportunities for practical application of study results to promote good practices in organizations activating local societies, were sought.

There are only a few studies focussed on similar cognitive areas $[11,14,20]$. One of the reasons is scarcity of objective tools to measure the parameters of strength and flexibility exercises, which are currently regarded as necessary for maintaining optimal efficiency of the locomotor system. They form the strength and power of the muscles, prevent the loss of muscle mass, increase joint mobility while preventing injuries and chronic illness, such as osteoporosis, back pain and faulty posture $[21,22,23]$.

Statistical analyses demonstrated that in a typical week, less than half of the study participants (45\%) met the criteria 
contained in WHO recommendations on both intensity (MPA or VPA or equivalent) and total weekly time of exercise (150/75min). These recommendations, extended with the ACSM criteria concerning the frequency of exercise throughout the week (5 days MPA or 3 days VPA or equivalent), were met by only $25 \%$ of the population studied.

The ACSM criteria for the frequency of flexibility and resistance exercises were also not met by the majority of the study participants ( $70 \%$ and $82 \%$, respectively). All the criteria of the WHO recommendation were met by $18 \%$ of the participants, whereas the ACSM criteria were met by only $2 \%$.

The results of this study demonstrated that the important problem in the process of PA evaluation concerning the health benefits is not only the evaluation of meeting all the whole recommendations, but also the identification of their individual criteria which are most often neglected in a specific study group. This information represents a valuable indication for development of programmes for healthy physical activity, both for groups and in individual cases. In the light of this study, the need arises for development of PA programmes within social and professional groups, based on the criteria of recommendations for healthy physical activity.

In previous studies published by other authors, the criterion for the frequency of exercise has been the main cause of non-meeting the recommendations $[24,25,17]$. The minimum frequency of physical exercise should be performed three times a week, whereas optimal recommendation for contemporary adults is daily minimum physical activity with a moderate intensity of at least 30 minutes $[18,25]$.

The frequency of the exercise as a criterion for the PA level is justified by the physiological phenomenon of the elevated rate of post-exercise recovery (post-exercise supercompensation) that takes up to 48 hours following the exercise. In this time, the body recovers with an around 10\% excess and is able to be involved in higher exercise [27], whereas the training sessions performed at least every other day are necessary for utilization of the effects of the previous effects.

In this light, ACSM recommendations seem to be more restrictive than those proposed by the WHO since they determine the minimal frequency of PA throughout the week, but they are also the most universal from the aspect of the choice of prerequisite criteria for evaluation of the healthy physical activity.

The findings of this study are partially consistent with the data documented by other authors, e.g., Chastin et al. [11] demonstrated that the percentage of people who meet the ACSM criterion concerning duration of endurance exercise $(5 \times 30 \mathrm{~min})$ accumulated in 10 -minute sections was $1 \%$. A similar low percentage $(3.5 \pm 0.3 \%)$ of adults who met the above criterion was documented in a study by Troiano et al. [10]. Other studies have shown that the percentage of people meeting recommendations for healthy physical activity is decreasing as the number of the criteria rises [11, 14], which is consistent with the findings of the presented study.

Contrary to the widely documented gender differences in physical activity participation $[29,30]$, there were no statistically significant differences in volume and frequency of physical activity, nor in meeting individual criteria and full recommendations between men and women in this study. The possible cause of the lack of such a diversity in the current study is the fact that the male and female members of examined NGOs regularly met together to participate in leisure physical activity. These participants are usually more aware of the positive influence of physical activity on overall health, and consequently they are more determined to undertake physical efforts, regardless of the gender differences in the free time budgets indicated as a frequent cause of diversity in the implementation of this health behaviour [31]. A similar observation was noted by Hirvensalo et al [32] in Finnish adults who are considered one of the most physically active societies in Europe.

In conclusion, the level of physical activity of the study participants with respect to recommendations developed by the WHO and ACSM was typically insufficient for maintaining or improving health. The negative aspect of the above conclusion is magnified by the fact that the study participants were people who were involved in regular physical activity.

In the view of the above findings, the need for increasing the strength and flexibility exercises in NGOs focused on the popularization of leisure-time physical activity seems to be an important practical conclusion to the current study.

The innovative approach in the study was the combination of objective and subjective research procedures to evaluate strength and flexibility exercises. Consequently, unlike the previous studies conducted in Poland, in the current study all the criteria for the healthy level of physical activity recommended by the ACSM were evaluated. The usefulness of this solution should be verified in further research.

Limitations. The relatively low sample size representing one geographical region seems to be the main limitation of the study. A limited quantity of Actigraphs, which are expensive tools for PA assessment and seldom used in the domestic studies, determined the decision to reduce the area of investigation. Additionally, in accordance with suggestions by the European Comission [33] to raise the reliability of PA evaluation, two methods of its diagnosis were used simultaneously and the precondition of consistency between times of activity declared in the Activity Logs and recorded by ActiGraphs as the criterion of inclusion a subject to analysis was introduced. Non-meeting this criterion led to a further reduction by $20 \%$ in the number of subjects finally included in analysis. A similar procedure is not entirely feasible in population-based studies, but it can be used to support them in smaller groups, e.g. in pilot studies or initial research.

\section{CONCLUSIONS}

1) The level of physical activity in the men and women who participated in the study was insufficient ton comply with the recommendations of ACSM and WHO experts. The negative aspect of the above findings is magnified by the fact that as members of NGOs promoting a healthy lifestyle, the study participants were involved in regular physical activity.

2) The most frequent cause of non-meeting the criteria of the health-oriented physical activity recommended by the ACSM was insufficient frequency of the weekly resistance exercises and flexibility exercises.

3) For evaluation of the level of physical activity and potential health benefits, it is useful to evaluate not only meeting all the recommendations, but also the individual criteria, which can support the programming of health-oriented physical activity in individuals or different social groups. 


\section{REFERENCES}

1. Blair SN, LaMonte MJ, Nichaman MZ. The evolution of physical activity recommendations: how much is enough? The Am J Clin Nutr. 2004; 79: 913-920.

2. Powell KE, Paluch AE, Blair SN. Physical activity for health: What kind? How much? How intense? On top of what? Annu Rev Public Health. 2011; 32(1): 349-365.

3. Brown WJ, Bauman AE, Bull FC, Burton NW. Development of evidence-based physical activity recommendations for adults (18-64 years): report prepared for the Australian Government Department of Health. Australian Government Department of Health, 2013.

4. American College of Sports Medicine. Roundtable on exercise guidelines for cancer survivors. J ACSM. 2010: 1409-1426.

5. Huai P, Xun H, Reilly KH, Wang Y, Ma W, Xi B. Physical Activity and Risk of Hypertension. A Meta-Analysis of Prospective Cohort Studies. Hypertension. 2013; 62(6): 1021-1026.

6. Stephens SK, Cobiac LJ, Veerman JL. Improving diet and physical activity to reduce population prevalence of overweight and obesity: an overview of current evidence. Prev Med. 2014; 62: 167-178.

7. Lambert EV, Bull F. Public health recommendations for physical activity in the prevention of type 2 diabetes mellitus. Med Sport Sci. 2014; 60: 130-140.

8. Abioye AI, Odesanya MO, Abioye AI, Ibrahim NA. Physical activity and risk of gastric cancer: a meta-analysis of observational studies. $\mathrm{Br}$ J Sports Med. 2015; 49(4): 224-229.

9. Rahl RL. Physical Activity and Health Guidelines: Recommendations for Various Ages, Fitness Levels, and Conditions from 57 Authoritative Sources. Chamapaign: Human Kinetics Publishers; 2010.

10. American College of Sport Medicine. General Principles of Exercise Prescription. ACSM's Guidelines for Exercise Testing and Prescription. Lippincott, Williams and Wilkins, 2010.

11. Troiano RP, Berrigan D, Dodd KW, Masse LC, Tilert T, McDowell M. Physical activity in the United States measured by accelerometer. Med Sci Sports Exerc. 2008; 40: 181-188.

12. Chastin SFM, Dall PM, Tigbe WW, Grant MP, Ryan CG, Rafferty D, et al. Compliance with physical activity guidelines in a group of UKbased postal workers using an objective monitoring technique. Eur J Appl Physiol. 2009; 106: 893-899.

13. Nawrocka A, Prończuk A, Mynarski W, Garbaciak W. Physical activity of top level managers in the context of the public health recommendations. Med Pr. 2012; 63(3): 271-279.

14. Mynarski W, Rozpara M, Nawrocka A, Borek Z, Powerska A, Garbaciak W. Physical activity of middle-age adults aged 50-65 years in view of health recommendations. Eur Rev Aging Phys Act. 2014; 11(2): 141-147.

15. Sheers T, Philippaerts R, Lefevre J. Compliance with different physical activity recommendations and its association with socio-demographic characteristics using an objective measure. BMC Public Health. 2013; 13: $136-145$.

16. Mutikainen S, Helander E, Pietilä J, Korhonen I, Kujala UM. Objectively measured physical activity in Finnish employees: a cross-sectional studies. BMJ Open Journal. 2014; 4: e005927.
17. Marques A, Sarmento H, Martins J, Nunes LS. Prevalence of physical activity in European adults - Compliance with the World Health Organization's physical activity guidelines. Prev med. 2015; 81:333-338.

18. Van Bui T, Blizzard CL, Luong KN, Le Van Truong N, Tran BQ, Otahal P. Physical Activity in Vietnam: Estimates and Measurement Issues. PloS one. 2015; 10(10): e0140941.

19. World Health Organization. Global recommendations on physical activity for health. WHO Library Cataloguing-in-Publication Data, 2010.

20. American College of Sport Medicine. General Principles of Exercise Prescription. ACSM's Guidelines for Exercise Testing and Prescription. Lippincott, Williams and Wilkins, 2010.

21. Chaix B, Kestens Y, Duncan S, Merrien C, Thierry B, Pannier B, et al. Active transportation and public transportation use to achieve physical activity recommendations? A combined GPS, accelerometer, and mobility survey study. Int J Behav Nutr Phys Act. 2014; 11: 124.

22. Westcott WL. Resistance Training is Medicine: Effects of Strength Training on Health. Curr Sports Med Rep. 2012; 11(4): 209-216.

23. Battaglia G, Bellafiore M, Caramazza G, Paoli A, Palma A. Changes in spinal range of motion after a flexibility training program in elderly women. Clin Interv Aging. 2014; 9: 653-660.

24. Maté-Muñoz JL, Monroy AJA, Jiménez PJ, Garnacho-Castaño MV. Effects of instability versus traditional resistance training on strength, power and velocity in untrained men. J Sports Sci Med. 2014; 13(3): $460-468$.

25. Bryan SN, Katzmarzyk PT. Are Canadians meeting the guidelines for moderate and vigorous leisure-time physical activity? Appl Physiol Nutr Metab. 2009; 34(4): 707-715.

26. Chomistek AK, Cook NR, Flint AJ, Rimm EB. Vigorous-intensity leisure-time physical activity and risk of major chronic disease in men. Med Sci Sports Exerc. 2012; 44(10): 1898-1905.

27. KahlmeierS, Wijnhoven TMA, Alpiger P, Schweizer C, Breda J, Martin BW. National physical activity recommendations: systematic overview and analysis of the situation in European countries. BMC Public Health. 2015; 15(1): 1-14.

28. Astrand PO. Why Excercise? Med Sport. 2000; 4(2): 83-100.

29. Baptista F, Santos DA, Silva AM, Mota J, Santos R, Vale S, et al. Prevalence of the Portuguese Population Attaining Sufficient Physical Activity. Med Sci Sports Exerc. 2012; 44(3): 466-473.

30. Bauman A, Bull F, Chey T, Craig CL, Ainsworth BE, Sallis JF, et al. The International Prevalence Study on Physical Activity: results from 20 countries. Int J Behav Nutr Phys Act. 2009; 6(1): 21.

31. Puiato D, Rozpara M, Mynarski W, Łoś A, Królikowska B. Physical activity of adult residents of Katowice and selected determinants of their occupational status and socio-economic characteristics. Med Pr. 2013; 64(5): 649-657.

32. Hirvensalo M, Telama R, Schmidt MD, Tammelin TH, Yang X, Magnussen CG, et al. Daily steps among Finnish adults: Variation by age, sex, and socioeconomic position. Scand J Public Health. 2011; 39(7): 669-677.

33. European Comission. EU Physical Activity Guidelines. Recommended Policy Actions in Support of Health-Enhancing Physical Activity. Brussels: European Comission; 2008. 